\title{
An Analysis of School-Based Contextual Indicators for Possible Use in Widening Participation
}

\author{
Stephen Gorard ${ }^{1}$, Nadia Siddiqui ${ }^{1} \&$ Vikki Boliver ${ }^{2}$ \\ ${ }^{1}$ School of Education, Durham University, Durham, UK \\ ${ }^{2}$ School of Applied Social Sciences, Durham University, Durham, UK \\ Correspondence: Stephen Gorard, School of Education, Durham University, DH1 1TA, UK. E-mail: \\ s.a.c.gorard@durham.ac.uk
}

Received: January 24, 2017

Accepted: February 6, 2017

Online Published: May 21, 2017

doi:10.5539/hes.v7n2p79

URL: http://doi.org/10.5539/hes.v7n2p79

\begin{abstract}
This paper looks at the National Pupil Database for England in terms of variables that could be used by universities to help them assess undergraduate applications. Where a young person is obviously disadvantaged, this can be taken into account in contextualised admissions. Of the indicators available, which give the most accurate assessment of that context-singly or in combination? This paper looks at missing data, and what is known about students for whom data is missing. It looks at changes in indicators of potential disadvantage over time. And it looks at the relationship between all indicators and student attainment and progress at school. The safest and clearest indicators are the sex (male) and age in year (summer born) of a student but neither of these is currently considered in widening participation. Otherwise, the best general indicator is eligibility for free school meals (poverty), and this is best computed as the number of years a student has been known to be eligible. Having a special educational need is also a promising indicator, but doubts are raised about its validity and it anyway covers a wide range of factors, some of which are already dealt with by the education system. Very few students registered as living in care continue in education post-16, and this indicator could be used safely and to advantage. The rest, including area measures, school type, performance relative to school, ethnicity and first language are generally not safe to use.
\end{abstract}

Keywords: contexualised admissions, poverty gradient, social justice, National Pupil Database, free school meals

\section{Introduction}

The student intakes to universities in the UK are and have always been stratified socio-economic and other characteristics (Gorard et al., 2007) - perhaps more so in the UK than other developed countries (Jerrim \& Vignoles, 2015). Students from less advantaged social and economic backgrounds are under-represented, especially in the UK's most selective universities and in some subjects leading to professions (Broecke, 2015). In response to this, an increasing number of universities are using contextual data about prospective students' socioeconomic and educational circumstances to inform admission decision-making (Universities Scotland, 2016), in the same way that it has long been used in school performance and improvement (Gorard, 2000, 2010). The key issue is to know which indicators are available and appropriate to use for this purpose.

The paper looks at those indicators that could be used, and which form part of the National Pupil Database (NPD) for England. This means that they are officially required from schools, usually have a legal definition, and can be made easily available to admissions authorities. The paper provides a summary of the simple comparative methods used, before presenting the tabulated results for each possible indicator, and then summarising the implications for contextualised admissions.

\section{Method}

\subsection{Datasets}

The analyses in this paper are based on the National Pupil Database (NPD), with records for all pupils in England who ended Key Stage 4 (KS4) in 2012, 2014 and 2015, and KS5 in 2008. The records include the pupil background characteristics, school details, and attainment for every year that they were at school in England (11 years for those in England continuously). The IDACI scores, EverFSM6 and Years eligible for FSM variables 
are only available for the 2015 data. The more detailed breakdown of school type attended is only for the 2012 data. Key Stage 5 data (up to age 19) is only available here for the 2008 cohort. For all years, the detailed data does not cover the majority of private schools (they are not required to complete the annual census of school intakes). Therefore, this paper is chiefly about the $93 \%$ of pupils from state-maintained schools in England.

The possible variables for use with contextualised admissions concern the area of residence (IDACI score), school type and intakes, family income (variants of FSM-eligibility), and individual characteristics (such as sex, age, first language, ethnicity, and SEN status).

\subsection{Analyses}

Each possible context variable is considered in terms of its missing data, its links to all other potential context variables, and to variables representing attainment and progress at KS1, KS2 and KS4. Most analysis is simple. Some indicators are recoded to simplify them and some are presented in several ways (e.g., ethnicity is presented both as a binary flag and in terms of major ethnic groups). Real numbers are correlated with each other, real numbers are compared to categories by comparing means, and categorical variables are cross-tabulated.

School intakes are converted to segregation ratios for FSM-eligibility. These ratios are a measure of the extent to which each school takes more or less than its fair share of children living in poverty (Gorard et al., 2003). In order to estimate the possible impact of attending a school with others having higher or lower attainment, we run two similar regression models. Both uses the best 8 GCSE-equivalent capped points attained as the outcome variables. All prior measures for each pupil are used as possible predictors in the first stage of regression for both models. In the first regression, the average level of pupil poverty in each school is added as a second stage predictor. In the second model, the average attainment for each school is added.

The Key Stage 5 (post-compulsory) attainment data is considered in terms of who stays on in education after the age of 16, and who attains the equivalent of ABB, CCC, and EE at A-level (QCA, 750, 630, and 300 points).

\section{Results}

\subsection{The Index of Deprivation as a Child Indicator (IDACI)}

IDACI is an aggregated index representing the proportion of children under the age of 16 in any super output area in the UK, living in a low income household. This is a valid summary measure of child poverty in any area, even though there will inevitably be errors and missing data. Whether an individual child lives in a highly deprived area or not is also used or proposed in policy as an alternative indicator of individual disadvantage. This is not so clearly valid for such a purpose.

Perhaps most obviously, whether a child lives in a deprived area is only very loosely related to their own level of deprivation. The correlation between the number of years a student has been known to be eligible for free school meals (i.e., from a low income family) and their IDACI score is +0.4 . This means that only $16 \%$ of the variation in one can be predicted or explained by the other. Put another way, the number of students eligible for free school meals in 2015 was 78,902 of which less than $45 \%$ lived in the $20 \%$ most deprived IDACI areas, and 180,642 pupils had been eligible in the previous six years, of which less than $39 \%$ lived in these poorest areas. Therefore, it is clear that most poor children do not live in the poorest areas. The same is true of any available measure of disadvantage.

Potentially deprived children do live disproportionately in the $20 \%$ of areas with the highest proportion of poor children, but most of the potentially deprived children in England live elsewhere (Table 1). There are also proportionately more ethnic minority or special needs pupils who have joined their school recently and do not have English as their first language in the poorest 20\% IDACI areas. However, to use a pupil's high IDACI score as a measure of their disadvantage means that most disadvantaged pupils will then be ignored.

Table 1. Percentage of pupils with specified characteristics in the poorest $20 \%$ and other $80 \%$ of areas, England 2015

\begin{tabular}{lcc}
\hline & Above 0.505 IDACI & Below 0.505 IDACI \\
\hline FSM-eligible & 31.3 & 9.8 \\
EverFSM6 & 62.6 & 24.7 \\
Ethnic minority (not White UK) & 42.4 & 15.4 \\
SEN (any) & 26.7 & 15.4 \\
\hline
\end{tabular}




\begin{tabular}{lcc}
\hline English as additional language & 32.6 & 10.1 \\
Joined school in last two years & 4.8 & 2.7 \\
\hline
\end{tabular}

Note. 0.505 is the mean IDACI score for the $2015 \mathrm{KS} 4$ cohort.

An IDACI score is also surprisingly unstable, because families move while children are at school (Table 2). Using the 2015 IDACI score as a baseline, it has a correlation of 0.73 with the IDACI score for the same pupil's home address just after they started primary school. This means that only $53 \%$ of the variation is common between 2005 and 2015, and so any one year of IDACI scores is only a relatively weak indicator of the level of poverty that an individual has lived in for their entire school life. Of course, the scores could be averaged over the 11 years of school up to KS4, but this is made more difficult by the level of missing data. For a number of reasons, including unknown addresses, no documentation, and pupils moving from outside England, each year of IDACI scores has missing values. In 2015, 13.2\% of the 560,735 KS4 pupils in NPD had missing IDACI scores for at least one of the prior 10 years.

Table 2. Correlation between pupils' IDACI score in 2005 and every subsequent year, England 2015

\begin{tabular}{ll}
\hline & IDACI score 2005 \\
\hline IDACI score 2006 & 0.95 \\
IDACI score 2007 & 0.91 \\
IDACI score 2008 & 0.84 \\
IDACI score 2009 & 0.82 \\
IDACI score 2010 & 0.80 \\
IDACI score 2011 & 0.77 \\
IDACI score 2012 & 0.76 \\
IDACI score 2013 & 0.75 \\
IDACI score 2014 & 0.74 \\
IDACI score 2015 & 0.73 \\
\hline
\end{tabular}

This missing data matters because, as ever, the kind of pupils whose address is not known is not random in nature. A total of 1,183 pupils were missing IDACI scores for 2015 (the year when most of them sat for 16+ examinations). This is not many, but may be quite large in comparison to the pool of students who might be considered for contextualised admission to HE. The pupils with missing IDACI scores can have other missing data as well. But insofar as it is possible to tell they are much more likely to be from poor families, certain ethnic minorities, with special needs, and/or to have been recent arrivals in their schools (Table 3).

Table 3. Percentage of pupils with specified characteristics with and without IDACI scores, England 2015

\begin{tabular}{lcc} 
& Missing IDACI scores & All pupils \\
\hline FSM-eligible & 20.8 & 14.1 \\
EverFSM6 & 42.1 & 32.3 \\
Ethnic minority (Black) & 6.7 & 5.0 \\
SEN (any) & 24.3 & 17.0 \\
Joined school in last two years & 8.0 & 3.1 \\
\hline
\end{tabular}

Note. There is little difference in terms of first language spoken.

The pupils with missing IDACI scores also have markedly lower attainment throughout their schooling, and make less progress on average between Key Stages (Table 4). 
Table 4. Mean attainment scores of pupils with and without IDACI scores, England 2015

\begin{tabular}{lcc}
\hline & Missing IDACI scores & All pupils \\
\hline KS1 average points & 14.3 & 15.2 \\
KS2 average points & 20.7 & 26.0 \\
KS1 to KS2 value-added score & -0.05 & +0.10 \\
KS4 capped points & 272.6 & 308.1 \\
\hline
\end{tabular}

Therefore, ignoring cases with missing data when deciding which pupils are disadvantaged would be unjust because some of the most deprived and so most deserving of assistance would be put aside in favour of others. However, using the fact of missing data as an indicator in itself would also be unjust and would offer assistance to some of the least deprived pupils (who may simply have transferred from another home country of the UK). It would also provide an incentive for families not to provide clear data to schools and universities.

Overall then, IDACI is not a good, valid, and safe measure of individual circumstances, and should not be used as a variable for contextualised admissions.

\subsection{Type of School Attended}

Many HEIs are concerned with which school or type of school an applicant attended when considering applicants to undergraduate courses. Unfortunately, 6,276 pupils have no school type code at KS4, and a further 256 pupils attend schools whose admissions policy is unknown (Table 5).

Table 5. Number of pupils in each type of school, England 2012

\begin{tabular}{|c|c|c|c|c|c|c|c|c|c|c|}
\hline & $\begin{array}{c}\text { School not } \\
\text { known }\end{array}$ & Comprehensive & Selective & Modern & $\begin{array}{c}\text { Admissions } \\
\text { policy unknown }\end{array}$ & $\begin{array}{c}\text { Maintained } \\
\text { special }\end{array}$ & $\begin{array}{c}\text { Hospital/ } \\
\text { PRU }\end{array}$ & $\begin{array}{c}\text { Independent } \\
\text { special }\end{array}$ & $\begin{array}{c}\text { Independent } \\
\text { other }\end{array}$ & Total \\
\hline $\mathrm{N}$ pupils & 6276 & 512,586 & 22,667 & 22,179 & 256 & 9,643 & 10,346 & 522 & 47,282 & 631,757 \\
\hline
\end{tabular}

Where data are available for the latter two groups, these pupils with missing schools are clearly more disadvantaged, and have markedly lower than average attainment and progress (Tables 6 and 7). This leads to the usual problems with missing data. If these pupils are ignored when using a CA indicator based on school type then they are being unfairly disadvantaged even further. However, some of these pupils will not be disadvantaged at all, and merely have moved to or from the independent sector, or another home country, recently. Some may also be older than the rest of the cohort. This raises a further issue of which school a pupil is deemed to have attended. Is it the most recent, the earliest, the longest attended or something else?

Table 6. Percentage of pupils with specified characteristics by type of school, England 2012

\begin{tabular}{|c|c|c|c|c|c|c|c|c|c|c|}
\hline & $\begin{array}{l}\text { School not } \\
\text { known }\end{array}$ & Comprehensive & Selective & Modern & $\begin{array}{c}\text { Admissions policy } \\
\text { unknown }\end{array}$ & $\begin{array}{l}\text { Maintained } \\
\text { special }\end{array}$ & $\begin{array}{c}\text { Hospital/ } \\
\text { PRU }\end{array}$ & $\begin{array}{c}\text { Independent } \\
\text { special }\end{array}$ & $\begin{array}{c}\text { Independent } \\
\text { other }\end{array}$ & Total \\
\hline FSM-eligible & $*$ & 14.5 & 2.3 & 11.8 & 22.1 & 38.4 & 39.4 & 12.7 & $*$ & 14.3 \\
\hline SEN & $*$ & 12.3 & 6.4 & 26.0 & 85.9 & 99.9 & $*$ & 99.8 & $*$ & 22.5 \\
\hline Non-White & $*$ & 19.9 & 22.5 & 14.7 & 20.7 & 16.8 & $*$ & 19.0 & $*$ & 27.8 \\
\hline EAL & $*$ & 13.9 & 10.7 & 10.5 & 9.4 & 9.7 & $*$ & 10.0 & $*$ & 12.7 \\
\hline Joined last 2 years & $*$ & 2.6 & 0.3 & 3.1 & 3.5 & 5.9 & 49.8 & 13.2 & 0.8 & 3.2 \\
\hline KS4 Level 2 EM & 2.3 & 57.9 & 96.9 & 52.3 & 11.3 & 0.3 & 1.4 & 4.0 & 81.4 & 58.4 \\
\hline
\end{tabular}

Note. * Means too many missing values to compute.

It is also clear from Tables 6 and 7 that a simple binary variable representing maintained or independent schooling would not be appropriate for CA. The independent sector includes special schools with very low levels of attainment. The maintained sector includes selective schools and some comprehensives with very low levels 
of pupil disadvantage and high levels of attainment. The biggest attainment gap (from the overall average) occurs in maintained special schools, but there have been no moves to treat this type of school, or hospitals and PRUs, as a factor in contextualised admissions.

Table 7. Mean attainment scores of pupils by type of school, England 2012

\begin{tabular}{|c|c|c|c|c|c|c|c|c|c|c|}
\hline & $\begin{array}{l}\text { School not } \\
\text { known }\end{array}$ & Comprehensive & Selective & Modern & $\begin{array}{c}\text { Admissions policy } \\
\text { not known }\end{array}$ & $\begin{array}{c}\text { Maintained } \\
\text { special }\end{array}$ & $\begin{array}{c}\text { Hospital/ } \\
\text { PRU }\end{array}$ & $\begin{array}{c}\text { Independent } \\
\text { special }\end{array}$ & $\begin{array}{l}\text { Independent } \\
\text { other }\end{array}$ & Total \\
\hline KS1 average points & 12.10 & 15.51 & 19.24 & 14.83 & 7.31 & 5.82 & 12.50 & 8.89 & 17.38 & 15.47 \\
\hline KS2 average points & 23.15 & 27.68 & 32.15 & 26.85 & 18.93 & 17.02 & 24.11 & 20.00 & 30.12 & 27.67 \\
\hline KS1-2 CVA & -0.85 & -0.08 & +0.96 & -0.33 & -1.33 & -0.91 & -0.58 & -0.33 & +0.67 & -0.06 \\
\hline KS4 entries & 5.51 & 11.63 & 11.81 & 11.77 & 6.65 & 4.57 & 3.17 & 5.06 & 9.47 & 7.57 \\
\hline KS4 total points & 148.1 & 479.7 & 590.5 & 471.0 & 154.1 & 81.3 & 82.9 & 122.5 & 463.6 & 465.9 \\
\hline KS4 capped points & 145.3 & 342.5 & 416.3 & 332.9 & 134.7 & 74.3 & 80.3 & 112.2 & 379.6 & 337.0 \\
\hline KS2-KS4 best 8 CVA & * & -1.1 & +15.4 & +0.2 & -97.1 & -126.9 & * & -78.9 & * & -2.4 \\
\hline
\end{tabular}

Note. $13.6 \%$ of cases are missing KS1, 9.3\% missing KS2, and 14.8\% missing KS2 CVA data.

\subsection{School Intakes and Peer "Effect"}

Table 8 includes three estimates of the level of disadvantage in the school attended by each student- - the segregation ratios for 2005 (their first school) and 2015 (their KS4 school), plus the average number of years all pupils in that school have been eligible for FSM. There are generally noticeable but far from perfect correlations between each measure of individual and school-level disadvantage. Pupils in more disadvantaged schools have lower attainment and make less progress between Key Stages. In general, the strongest correlations between individual school-level variables involve the average number of years FSM, and this is used hereon.

Table 8. Correlations between school-level disadvantage and individuals, KS4 cohort, England 2015

\begin{tabular}{lccc}
\hline & Segregation 2005 & Segregation 2015 & FSM years mean \\
\hline Age in months & 0 & 0 & 0 \\
FSM 2005 & 0.40 & 0.09 & 0.07 \\
FSM 2015 & 0.27 & 0.29 & 0.30 \\
Years FSM by KS4 & 0.41 & 0.34 & 0.39 \\
Years FSM missing & 0.01 & 0.09 & 0.07 \\
IDACI 2005 & 0.63 & 0.53 & 0.57 \\
IDACI 2015 & 0.58 & 0.57 & 0.61 \\
KS1 average points & -0.22 & -0.23 & -0.31 \\
KS2 average points & -0.14 & -0.16 & -0.18 \\
N GCSE equivalent entries & -0.15 & -0.16 & -0.26 \\
Total GCSE capped points & -0.19 & -0.21 & -0.30 \\
Best 8 VA score & -0.12 & -0.11 & -0.17 \\
\hline
\end{tabular}

School-level disadvantage is linked to having higher proportions of pupils of some ethnic minorities (Black and Pakistani/Bangladeshi), EAL, SEN, student mobility, and lower attainment (Table 9). It could therefore be used as a proxy for individual disadvantage, but there is little or no point where individual data is available as well. 
Table 9. Means of school-level disadvantage for individuals, KS4 cohort, England 2015

\begin{tabular}{lc}
\hline & FSM years mean \\
\hline Males & 1.57 \\
Females & 1.53 \\
White & 1.39 \\
Black & 2.40 \\
Pakistani/Bangladeshi & 2.23 \\
Chinese & 1.49 \\
Other/mixed & 1.95 \\
English first language & 1.42 \\
English additional language & 2.37 \\
No SEN 2015 & 1.47 \\
SEN no statement & 1.76 \\
SEN statement & 2.61 \\
Not joined school last 2 years & 1.53 \\
Joined school last 2 years & 2.11 \\
Did not achieve 5+ GCSE A*-C with English and maths & 1.83 \\
Achieved 5+ GCSE A*-C with English and maths & 1.32 \\
Overall & 1.55 \\
\hline
\end{tabular}

In fact, the more usual proposal for contextualised admissions is not to use the average school deprivation or attainment, but to compare individual deprivation or attainment with the school average. This is supposed to identify pupils who have done better than their circumstances might suggest, and is based on the idea of a "peer" effect (Gorard, 2006).

Tables 10 and 11 show the results of a regression model "predicting" the KS4 outcomes for each pupil. In the first stage, $\mathrm{R}$ is 0.81 suggesting that about $65 \%$ of the variation can be explained or predicted by prior attainment and pupil background characteristics. The most important predictor is prior attainment at KS2. Adding the average level of deprivation of each school (means years FSM-eligibility per school) adds nothing to accuracy of the model. Pupil attainment here does not seem to be influenced by the type of pupils they go to school with.

Table 10. R from multi-stage regression models predicting total capped KS4 points, England 2015

\begin{tabular}{cc}
\hline Background predictors & 0.81 \\
\hline School level disadvantage & 0.81 \\
\hline
\end{tabular}

Table 11. Standardised coefficients from four multi-stage regression models predicting total capped KS4 points, England 2015

\begin{tabular}{ll}
\hline KS2 average points (prior attainment) & 0.56 \\
\hline KS1 average points (prior attainment) & 0.11 \\
Sex of pupil (female) & 0.07 \\
Month in year (summer born) & 0.04 \\
Number of years known to be FSM-eligible & -0.03 \\
FSM 2005 & -0.01 \\
FSM 2015 & -0.01 \\
Special need (SEN) & -0.08 \\
\hline
\end{tabular}




\begin{tabular}{lc}
\hline IDACI 2005 (deprivation) & -0.03 \\
IDACI 2015 (deprivation) & -0.02 \\
English as an additional language & 0.07 \\
Non-White UK (ethnic minority) & 0.04 \\
Joined school last 2 years & 0.07 \\
Average years FSM for all pupils in school & -0.07 \\
\hline
\end{tabular}

Very similar results emerge from the second model (Tables 12 and 13). Clearly, the first stage of the models is identical to above, predicting $65 \%$ of the variation in outcomes with prior attainment as the best single predictor. In the second stage, when school average points score is added the variation explained does increase by a very small amount $(\mathrm{R}=0.02,0.04 \%)$. Given the omitted variables (not available), missing data and level of imprecision in these predictors, this increase is not sufficient to base contextualised admissions on.

Table 12. R from multi-stage regression models predicting total capped KS4 points, England 2015

\begin{tabular}{cc}
\hline Background predictors & 0.81 \\
\hline School level attainment & 0.83 \\
\hline
\end{tabular}

Table 13. Standardised coefficients from four multi-stage regression models predicting total capped KS4 points, England 2015

\begin{tabular}{ll}
\hline KS2 average points (prior attainment) & 0.52 \\
\hline KS1 average points (prior attainment) & 0.09 \\
Sex of pupil (female) & 0.07 \\
Month in year (summer born) & 0.04 \\
Number of years known to be FSM-eligible & -0.03 \\
FSM 2005 & -0.01 \\
FSM 2015 & -0.01 \\
Special need (SEN) & -0.08 \\
IDACI 2005 (deprivation) & -0.03 \\
IDACI 2015 (deprivation) & -0.02 \\
English as an additional language & 0.07 \\
Non-White UK (ethnic minority) & 0.04 \\
Joined school last 2 years & 0.06 \\
Average GCSE points for all pupils in school & 0.21 \\
\hline
\end{tabular}

\subsection{FSM Eligibility}

Eligibility for FSM is a strong contender as a CA variable. However, as with all variables, some cases are missing a value. When the 2015 KS4 cohort started schooling, about 9\% of them had unknown FSM status. These pupils who have presumably arrived in the NPD system of England later are more likely to have joined their current school recently, be of an ethnic minority, and not speak English as their first language (Table 14). Yet those with no known FSM status are markedly less likely to be registered as having SEN_perhaps because they had had less time for this to be reported or because ethnic minorities are less likely to report SEN anyway (see below). This suggests that SEN is not an entirely valid measure of educational disadvantage. 
Table 14. Percentage of pupils with specified characteristics by FSM category, England 2015

\begin{tabular}{lcccc}
\hline & No FSM 2005 & FSM 2005 & Not known & All pupils \\
\hline Non-white & 15.4 & 29.8 & 48.7 & 20.8 \\
EAL 2015 & 8.2 & 18.1 & 62.1 & 14.7 \\
Ever EAL & 16.7 & 24.7 & 67.1 & 19.5 \\
SEN & 14.7 & 29.2 & 13.4 & 17.0 \\
Ever SEN & 36.7 & 62.3 & 31.6 & 40.5 \\
Joined last 2 years & 1.7 & 4.4 & 12.7 & 3.1 \\
\hline
\end{tabular}

Note. 49,671 pupils from a total of 560,735 with FSM data in 2015 had missing FSM data in 2005.

Those without valid FSM data in 2005 also have lower attainment than average-lower even than those known to be FSM-eligible (Table 15). However, they catch up rapidly.

Table 15. Mean scores of pupils in each FSM category, England 2015

\begin{tabular}{lcccc}
\hline & No FSM 2005 & FSM 2005 & Not known & All pupils \\
\hline Age in months & 69.51 & 69.54 & 69.89 & 69.55 \\
KS1 average points & 15.71 & 13.17 & 12.53 & 15.23 \\
KS2 total points & 41.55 & 34.68 & 39.17 & 40.23 \\
KS1-2 VA score & +0.07 & +0.08 & +1.36 & +0.10 \\
KS4 total points & 385.53 & 280.35 & 363.39 & 366.02 \\
KS4 capped points & 321.91 & 248.30 & 0.304 .87 & 308.12 \\
IDACI 2015 & 0.18 & 0.35 & $*$ & 0.22 \\
IDACI mean 2005-15 & 0.19 & & 0.37 & 0.22 \\
\hline
\end{tabular}

Leaving aside the missing cases, it is clear that pupils eligible for FSM at any stage of schooling are more disadvantaged on average in all other respects as well (Tables 16 and 17). They are more likely to be recent arrivals, from ethnic minorities, with English as an additional language, and special needs.

Table 16. Percentage of pupils with specified characteristics by FSM category, England 2015

\begin{tabular}{lccc}
\hline & No FSM 2015 & FSM 2015 & All pupils \\
\hline Non-white & 19.1 & 31.0 & 20.8 \\
EAL & 13.5 & 21.6 & 14.7 \\
Ever EAL & 18.1 & 27.8 & 19.5 \\
SEN & 14.6 & 31.7 & 17.0 \\
Ever SEN & 36.8 & 63.3 & 40.5 \\
Joined last 2 years & 2.8 & 5.4 & 3.1 \\
\hline
\end{tabular}

Table 17. Percentage of pupils with specified characteristics by FSM category, England 2015

\begin{tabular}{lccc}
\hline & Not EverFSM 2015 & EverFSM 2015 & All pupils \\
\hline Non-white & 16.6 & 29.4 & 20.8 \\
EAL 2015 & 12.2 & 19.7 & 14.7 \\
Ever EAL & 16.4 & 26.0 & 19.5 \\
SEN & 12.5 & 26.4 & 17.0 \\
Ever SEN & 32.3 & 57.7 & 40.5 \\
Joined last 2 years & 2.4 & 4.7 & 3.1 \\
\hline
\end{tabular}


FSM pupils have lower attainment at all stages of schooling, and they make less progress between Key Stages (Tables 18 and 19). They are also more likely to live in more deprived areas. FSM may be the best single indicator of relative disadvantage.

Table 18. Mean scores of pupils in each FSM category, England 2015

\begin{tabular}{lccc}
\hline & No FSM 2015 & FSM 2015 & All pupils \\
\hline Age in months & 129.55 & 129.55 & 129.55 \\
KS1 average points & 15.59 & 12.92 & 15.23 \\
KS2 total points & 41.14 & 34.72 & 40.23 \\
KS1-2 VA score & +0.11 & +0.07 & +0.10 \\
KS4 total points & 381.17 & 273.73 & 366.02 \\
KS4 capped points & 318.85 & 242.77 & 308.12 \\
IDACI 2015 & 0.20 & 0.35 & 0.22 \\
IDACI mean 2005-15 & 0.20 & 0.35 & 0.22 \\
Years SEN & 1.89 & 3.78 & 2.16 \\
\hline
\end{tabular}

Table 19. Mean scores of pupils in each FSM category, England 2015

\begin{tabular}{lccc}
\hline & Not EverFSM 2015 & EverFSM 2015 & All pupils \\
\hline Age in months & 129.56 & 129.55 & 129.55 \\
KS1 average points & 16.01 & 13.54 & 15.23 \\
KS2 total points & 42.38 & 35.83 & 40.23 \\
KS1-2 VA score & +0.12 & +0.05 & +0.10 \\
KS4 total points & 399.42 & 295.98 & 366.02 \\
KS4 capped points & 381.17 & 260.01 & 308.12 \\
IDACI 2015 & 0.17 & 0.32 & 0.22 \\
IDACI 2005-2015 & 0.17 & 0.33 & 0.22 \\
\hline
\end{tabular}

Looking at the number of years a pupil has been eligible for FSM changes the picture slightly. Many characteristics such as EAL, and mobility between schools are largely unrelated to the number of years a pupil has been FSM-eligible (Table 20). The key is simply whether a pupil has ever been eligible. However, the longer-term poorer pupils are more likely to be from an ethnic minority, and much less likely to be in a selective grammar school.

Table 20. Percentage of pupils with specified characteristics by number of years FSM, England 2015

\begin{tabular}{|c|c|c|c|c|c|c|c|c|c|c|c|}
\hline & Never FSM & 1 & 2 & 3 & 4 & 5 & 6 & 7 & 8 & 9 & 10 \\
\hline Grammar school & 5.4 & 1.8 & 1.5 & 1.2 & 1.0 & 0.8 & 0.7 & 0.6 & 0.5 & 0.3 & 0.4 \\
\hline SEN & 12.2 & 18.5 & 20.2 & 22.2 & 23.6 & 24.0 & 25.6 & 27.1 & 28.7 & 31.6 & 33.8 \\
\hline EAL & 11.5 & 19.2 & 20.5 & 18.1 & 18.1 & 17.7 & 17.7 & 19.1 & 20.5 & 20.7 & 21.0 \\
\hline Non-White & 15.8 & 26.1 & 27.7 & 27.6 & 28.5 & 28.0 & 28.1 & 29.7 & 31.7 & 31.9 & 31.6 \\
\hline Joined last 2 years & 2.2 & 5.3 & 4.4 & 3.6 & 3.9 & 4.2 & 4.5 & 4.6 & 4.8 & 5.1 & 2.9 \\
\hline
\end{tabular}

It is shocking that the only group with positive value-added scores on average at KS4 are those never eligible for FSM, otherwise the value-added score declines in a clear progression with every year of eligibility (Table 21). 
Poorer children start school with lower attainment than their peers, and then continue to lose ground over time, and the poorer they are the more they fall behind.

Table 21. Mean attainment scores of pupils by number of years FSM, England 2015

\begin{tabular}{lccccccccccc}
\hline & Never FSM & 1 & 2 & 3 & 4 & 5 & 6 & 7 & 8 & 9 & 10 \\
\hline KS1 points & 16.0 & 14.5 & 14.3 & 14.0 & 13.9 & 13.6 & 13.5 & 13.2 & 12.9 & 12.5 & 12.4 \\
KS2 points & 21.1 & 19.0 & 18.7 & 18.6 & 18.2 & 17.9 & 17.7 & 17.7 & 17.3 & 16.7 & 16.5 \\
KS4 entries & 9.54 & 8.78 & 8.64 & 8.59 & 8.46 & 8.35 & 8.24 & 8.12 & 8.00 & 7.70 & 7.71 \\
KS4 points & 332 & 288 & 281 & 277 & 272 & 266 & 261 & 256 & 251 & 237 & 238 \\
Best 8 VA & +8.7 & -12.4 & -16.0 & -18.8 & -22.8 & -25.1 & -30.3 & -32.0 & -36.0 & -44.6 & -42.5 \\
IDACI & 0.17 & 0.27 & 0.28 & 0.29 & 0.31 & 0.32 & 0.33 & 0.35 & 0.36 & 0.38 & 0.39 \\
Month in year & 6.51 & 6.52 & 6.51 & 6.52 & 6.55 & 6.49 & 6.52 & 6.60 & 6.55 & 6.47 & 6.51 \\
FSM years mean & 1.27 & 1.81 & 1.91 & 1.98 & 2.05 & 2.12 & 2.24 & 2.36 & 2.48 & 2.63 & 2.73 \\
\hline
\end{tabular}

A final consideration is the extent to which FSM pupils are under-represented in post-16 education and attainment. Around $13 \%$ of pupils were eligible for FSM in the 2008 KS5 cohort, but they were only $8 \%$ of those who continued post- 16 and only $5 \%$ of those who attained ABB grades or equivalent at A-level enabling them to enter the more selective universities (Table 22). At each step in Table 22, the proportion of FSM-eligible students declines in proportion to non-FSM students (row \%) and in proportion to the original number (column \%). This could mean that FSM students are substantively under-represented in HE.

Table 22. Proportions of pupils continuing with post-16 education, by FSM, KS5 cohort, England 2008

\begin{tabular}{lccccccc}
\hline & non-FSM & Column $\%$ & Row $\%$ & FSM & Column $\%$ & Row \% & Total \\
\hline Total at KS4 & 516,290 & 100 & 86.9 & 78,510 & 100 & 13.1 & 594,800 \\
Continued post-16 & 289,073 & 56.0 & 92.2 & 24,564 & 31.3 & 7.8 & 313,637 \\
Achieved EE+ & 248,388 & 48.1 & 92.7 & 19,559 & 24.9 & 7.3 & 267,947 \\
Achieved CCC+ & 172,267 & 33.4 & 94.7 & 10,494 & 13.4 & 5.7 & 182,761 \\
Achieved ABB+ & 126,227 & 24.5 & 95.2 & 6,325 & 8.1 & 4.8 & 132,552 \\
\hline
\end{tabular}

Note. $\mathrm{EE}+$ at A level or equivalent in QCA points etc.

In Table 22, 25\% of the original FSM-eligible students achieved EE+ at A level or equivalent (which could be considered the minimum entry grade for HE), and 18\% entered HE the following year (BIS 2013), representing $72 \%$ of those with EE or equivalent. Of the non-FSM-eligible students, $48 \%$ attained $\mathrm{EE}+$, and $34 \%$ entered $\mathrm{HE}$, representing $73 \%$. This means that FSM-eligible students entered HE in almost direct proportion to their KS4 cohort base.

In Table 22, $8 \%$ of the original FSM-eligible students achieved ABB+ at A-level or equivalent (which could be considered the minimum entry grade for $\mathrm{HE}$ ), and $4 \%$ entered the most selective HEIs (defined as the top third of HEIs when ranked by mean UCAS tariff score from the top three A level grades of entrants) the following year (BIS, 2013). This represents $50 \%$ of those with $\mathrm{ABB}+$ or equivalent, and means that FSM-eligible students entered even the most selective HEIs (as defined here) in proportion to their KS4 cohort base or better.

\subsection{Living in Care}

Pupils living in care (at KS5) are more disadvantaged in other ways as well, but perhaps not by as much as might be expected (Table 23). 
Table 23. Percentage of pupils with specified characteristics and living in care, KS5 cohort, England 2008

\begin{tabular}{lcc}
\hline & Living in care & Not living in care \\
\hline Non-white UK & 22.3 & 16.0 \\
FSM-eligible & 16.0 & 13.2 \\
English as additional language & 12.9 & 10.0 \\
SEN & 59.9 & 18.0 \\
\hline
\end{tabular}

However, these students living in care have lower average attainment than others at every stage of education (Table 24).

Table 24. Correlations between attainment and living in care, KS5 cohort, England 2008

\begin{tabular}{lcc}
\hline & Living in care & Not living in care \\
\hline KS2 average points & 23.0 & 27.0 \\
KS4 number of entries & 6.7 & 9.7 \\
KS4 capped points & 163.8 & 292.6 \\
KS5 points & 575.6 & 726.0 \\
\hline
\end{tabular}

Very few pupils living in care continue to KS5 (Table 25). This all means that it would be reasonably safe to use living in care as an indicator for CA-there is clear disadvantage and there are unlikely to be any false positives. As with FSM-eligible students, those living in care reduce at every stage in Table 25, but unlike FSM students those living in care are probably not proportionately represented in HE.

Table 25. Proportions of pupils continuing with post-16 education, by in-care, England 2008

\begin{tabular}{lccccccc}
\hline & In-care & Column $\%$ & Row $\%$ & Not in-care & Column $\%$ & Row \% & Total \\
\hline Total at KS4 & 4,372 & 100 & 0.7 & 590,428 & 100 & 99.3 & 594,800 \\
Continued post-16 & 691 & 15.8 & 0.2 & 312,946 & 53.0 & 99.8 & 313,637 \\
Achieved EE+ & 489 & 11.2 & 0.2 & 267,458 & 45.3 & 99.8 & 267,947 \\
Achieved CCC+ & 255 & 5.8 & 0.1 & 182,506 & 30.9 & 99.9 & 182,761 \\
Achieved ABB+ & 158 & 3.6 & 0.1 & 132,391 & 22.4 & 99.9 & 132,552 \\
\hline
\end{tabular}

\subsection{Ethnicity}

Ethnic origin has been proposed as a contextualised admissions indicator, with the chief advantage that it is about individuals and their close family. The proposal is predicated on the fact that there are substantial differences between self-reported ethnic groups, their indicators of disadvantage (Table 26), and their attainment at school (Table 27). White and especially Chinese pupils are less likely to come from low-income families, whereas Black, "mixed" and pupils from any other ethnicity are more likely to be FSM-eligible. White pupils are most likely to have English as their first language, but Chinese and pupils with any other ethnicity are most likely not to. Chinese and south Asian pupils are less likely to have a reported special education need, whereas Black and pupils with unknown ethnicity are more likely to. Those with unknown or any other ethnicity are more likely to have moved schools recently (Table 26).

Table 26. Percentage of pupils with specified characteristics by ethnicity, England 2015

\begin{tabular}{lcccccccc}
\hline & White & Asian & Black & Chinese & Mixed & Any other & Not known & All pupils \\
\hline FSM-eligible & 12.3 & 19.3 & 25.5 & 7.1 & 20.0 & 26.6 & 16.6 & 14.1 \\
EverFSM6 & 28.8 & 40.5 & 57.9 & 17.2 & 45.2 & 51.8 & 38.2 & 32.3 \\
\hline
\end{tabular}




\begin{tabular}{lcccccccc}
\hline EAL & 4.5 & 75.7 & 43.0 & 74.7 & 14.5 & 80.4 & 21.8 & 14.7 \\
SEN (any) & 17.4 & 12.7 & 18.8 & 7.9 & 17.8 & 16.3 & 18.9 & 17.0 \\
Joined last 2 years & 2.7 & 3.8 & 6.2 & 5.0 & 4.1 & 8.9 & 6.9 & 3.1 \\
\hline
\end{tabular}

White, Chinese, and to a lesser extent pupils with unknown ethnicity have higher average attainment at KS1 and KS2. Black, Chinese and "any other" ethnicity pupils make the most progress from KS1 to KS2. Asian pupils tend to have low attainment at KS1, and especially KS2, but Chinese and Asian pupils have higher average attainment at KS4 (Table 27).

Table 27. Mean attainment scores of pupils by ethnicity, England 2015

\begin{tabular}{lcccccccc}
\hline & White UK & Asian & Black & Chinese & Mixed & Any other & Not known & All pupils \\
\hline KS1 average points & 15.38 & 14.36 & 14.03 & 16.21 & 15.23 & 13.90 & 14.93 & 15.23 \\
KS2 average points & 20.46 & 17.49 & 19.01 & 21.55 & 19.98 & 18.64 & 20.22 & 20.10 \\
KS1 to KS2 VA & +0.05 & +0.23 & +0.51 & +0.37 & +0.24 & +0.52 & +0.17 & 0.10 \\
KS4 capped points & 306.4 & 323.5 & 302.5 & 372.9 & 311.2 & 313.0 & 297.0 & 308.1 \\
IDACI score & 0.18 & 0.33 & 0.40 & 0.23 & 0.27 & 0.36 & 0.24 & 0.22 \\
\hline
\end{tabular}

Although there are some clear differences between ethnic groups on each variable in Tables 26 and 27, there are few clear overall patterns. Black pupils tend to be the most disadvantaged and have the lowest attainment despite making better than average progress. Chinese pupils are most likely to speak English as a second language but otherwise report the least disadvantage and have the highest attainment. The relative attainment figures are anyway only averages. The attainment patterns for all ethnic groups overlap greatly for the most part (Table 28). Every ethnic group includes pupils with no KS4 qualifications at all, and each has pupils with very high attainment indeed. In 2015, the highest attaining Black pupils got clearly higher scores than the highest attaining Chinese pupils, despite the lower overall average.

Table 28. Highest and lowest KS4 attainers by ethnicity, England 2015

\begin{tabular}{lcccccccc}
\hline & White UK & Asian & Black & Chinese & Mixed & Any other & Not known & All pupils \\
\hline Highest attainer & 530.50 & 502.00 & 492.50 & 485.00 & 483.00 & 479.64 & 479.64 & 530.50 \\
Lowest attainer & 0 & 0 & 0 & 0 & 0 & 0 & 0 & 0 \\
\hline
\end{tabular}

As with any official indicator, ethnicity has missing values. In 2015, 5,852 pupils out of 560,735 were missing data on their ethnic group (unknown, refused, blank). And as ever, these missing values are not missing at random. These pupils are more disadvantaged than average in every category in Table 26, and live in slightly more disadvantaged areas (Table 27). They start with lower than average KS1 scores, and end with lower KS4 scores. Ignoring cases with missing values would therefore neglect some of the most disadvantaged pupils, but treating all pupils with missing ethnicity data as disadvantaged would also be wrong, and would erroneously include some of the most advantaged pupils.

Like a pupil's sex and unlike their FSM-eligibility, self-reported ethnicity would not be expected to change much for many pupils over time. Yet from 2006 to 2015 at least 37,536 cases or $6.7 \%$ changed their recorded ethnic group at least once, often several times. This figure ignores the missing data (more frequent in earlier years), and also ignores 2005 which uses a different classification (and so would add considerably more "change" over time). Several cases change from one ethnic value to another and back, sometimes with missing data in-between. Commonly pupils' status moves over time from a specific ethnic category to mixed or any other ethnic group, or from unknown to known. A few cases have three or more distinct classifications over time. As with the missing category (above) but to a far greater degree, pupils with more than one ethnic category are more disadvantaged and have lower attainment (Tables 29 and 30). In particular, they are much more likely to be FSM-eligible and have English as an additional language. It is not really feasible to use changed ethnicity over time as an indicator for contextualised admissions, for many of the same reasons as for cases missing data. But what this analysis 
shows is that to use the ethnicity status from any one year may be unfair to those pupils with changes over time, by portraying them as being in one ethnic group that might be in error and might suggest an inappropriate level of relative disadvantage.

Table 29. Percentage of pupils with specified characteristics with and without changed ethnicity value, England 2015

\begin{tabular}{lcc}
\hline & Changed Ethnicity & All pupils \\
\hline FSM-eligible & 20.9 & 14.1 \\
EverFSM6 & 46.3 & 32.3 \\
English as additional language & 29.4 & 14.7 \\
SEN (any) & 19.8 & 17.0 \\
Joined school in last two years & 5.2 & 3.1 \\
\hline
\end{tabular}

Table 30. Mean attainment scores of pupils with and without changed ethnicity value, England 2015

\begin{tabular}{lcc}
\hline & Changed Ethnicity & All pupils \\
\hline KS1 average points & 14.60 & 15.23 \\
KS2 average points & 25.43 & 26.01 \\
KS1 to 2 value-added score & 0.21 & 0.10 \\
KS4 capped points & 301.30 & 308.12 \\
IDACI score & 0.28 & 0.22 \\
\hline
\end{tabular}

In summary, it is not clear that simply having any specific ethnic origin is necessarily a disadvantage in terms of attainment at school, in a way that would not be picked up by other indicators. And this is reflected in the overall figures for participation and attainment at KS5 (Table 31). Around $51 \%$ of the majority White students continue post-16, and $44 \%$ attain minimum level 3 qualifications at KS5. Ethnic minority students are more likely to continue and more likely to attain level 3 . However, the fires are balanced (22\%) for those gaining high grades of the kind that may get then admitted to the most selective universities.

Table 31. Proportions of pupils continuing with post-16 education, by ethnicity, all pupils in England 2008

\begin{tabular}{lccccccc}
\hline & White & Column $\%$ & Row $\%$ & Non-White & Column $\%$ & Row \% & Total \\
\hline Total at KS4 & 499,380 & 100 & 84.0 & 95,420 & 100 & 16.0 & 594,800 \\
Continued post-16 & 256,011 & 51.3 & 81.6 & 57,626 & 60.4 & 18.4 & 313,637 \\
Achieved EE+ & 218,698 & 43.8 & 81.6 & 49,249 & 52.2 & 18.4 & 267,947 \\
Achieved CCC+ & 151,283 & 30.3 & 82.8 & 31,478 & 33.0 & 17.6 & 182,761 \\
Achieved ABB+ & 111,485 & 22.3 & 84.1 & 21,067 & 22.1 & 15.9 & 132,552 \\
\hline
\end{tabular}

A similar picture emerges from a more detailed consideration (Table 32). White, Asian, mixed, and other ethnicity students all have about the same chance of achieving ABB or better at KS5. Black and unclassified students have lower chance, and Chinese origin students a much better one. If ethnicity is used as a CA indicator then it is important to note that it is Black students currently finding it hardest, on average, to convert participation into the highest grades. 
Table 32. Proportions of pupils continuing with post-16 education, by ethnicity, all pupils in England 2008

\begin{tabular}{lcccccccc}
\hline & Any other & Asian & Black & Chinese & Mixed & Unclassified & White & Total \\
\hline Total at KS4 & 5,058 & 37,577 & 21,993 & 2,253 & 13,395 & 15,144 & 499,380 & 594,800 \\
\%Continued post-16 & 60.9 & 67.3 & 57.5 & 84.0 & 55.0 & 48.6 & 51.3 & 52.7 \\
\%Achieved EE+ & 51.1 & 57.2 & 48.4 & 77.1 & 46.6 & 40.9 & 43.8 & 45.0 \\
\%Achieved CCC+ & 33.9 & 37.2 & 27.4 & 61.8 & 31.6 & 27.1 & 30.3 & 30.7 \\
\%Achieved ABB+ & 23.1 & 24.7 & 16.1 & 49.9 & 22.7 & 19.3 & 22.3 & 22.3 \\
\hline
\end{tabular}

\subsection{First Language}

In $2015,14.7 \%$ of pupils were recorded as having English as a second or additional language. In addition, there were 5,974 pupils whose first language was not recorded. In most respects, pupils whose first language is not known are more similar to those for whom English is not the first language (Table 33). Therefore, ignoring missing values when proposing an indicator for contextualised admissions would again unfairly disadvantage some of the more disadvantaged - both by ignoring them for CA and by making it easier for those with a value for that indicator to obtain one of the finite number of places in HE. If places in HE are not finite, then open access would be easier and fairer, and selection would only be maintained by those wishing to select for HEIs within the sector. If, on the other hand, missing data were itself treated as an indicator for CA, this would perversely encourage applicants to be unclear about their first language.

Pupils recorded as having English as an additional language tend to be from poorer families, and ethnic minorities, and to have arrived in their current school recently. They were less likely to be recorded as having SEN.

Table 33. Percentage of pupils with specified characteristics by first language, England 2015

\begin{tabular}{lcccc}
\hline & English & Other & Not known & All pupils \\
\hline FSM-eligible & 13.0 & 21.0 & 18.0 & 14.1 \\
EverFSM6 & 30.4 & 43.6 & 42.1 & 32.3 \\
Non-White UK & 11.3 & 76.6 & 64.7 & 20.8 \\
SEN & 17.4 & 14.3 & 17.2 & 17.0 \\
Joined last 2 years & 2.4 & 7.3 & 6.2 & 3.1 \\
\hline
\end{tabular}

Note. Not known includes refused, pending and not known (whether believed to be English or other).

At the start of schooling, it is therefore not surprising that pupils whose first language is not English have lower attainment, but they make considerably more progress. By KS4 there is little overall difference between the three language groups in terms of attainment, confirming that for most pupils having English as an additional language is not a (permanent) indicator of disadvantage (Table 34). This suggests that EAL, in itself, is not an appropriate variable for $\mathrm{CA}$.

Table 34. Mean attainment scores of pupils by first language, England 2015

\begin{tabular}{lcccc}
\hline & English & Other & Not known & All pupils \\
\hline KS1 average points & 15.38 & 13.78 & 14.44 & 15.23 \\
KS2 average points & 20.42 & 17.83 & 18.31 & 20.10 \\
KS1 to 2 value-added score & +0.07 & +0.36 & +0.41 & +0.10 \\
KS4 capped points & 307.95 & 309.30 & 306.87 & 308.12 \\
IDACI score & 0.19 & 0.35 & 0.30 & 0.22 \\
\hline
\end{tabular}


As with FSM, it is worthwhile considering how long a pupil has been registered as being EAL. In general, pupils with English as an additional language are disadvantaged in terms of other available indicators but perhaps less so with every year (Table 35). They are more mobile, non-White, and from poorer families and areas, and this is more so the more years they are known to have been reported as having EAL. However, they are somewhat less likely to have SEN. It is possible that EAL is somehow used as a label that stands instead of SEN for some pupils. If so, this would bring the validity of both labels into question to some extent.

Table 35. Percentage of pupils with specified characteristics by number of years EAL, England 2015

\begin{tabular}{|c|c|c|c|c|c|c|c|c|c|c|c|c|c|}
\hline & Never EAL & 1 & 2 & 3 & 4 & 5 & 6 & 7 & 8 & 9 & 10 & 11 & EverEAL \\
\hline FSM-eligible & 14 & 19 & 15 & 15 & 17 & 17 & 16 & 18 & 19 & 18 & 22 & 25 & 20 \\
\hline EverFSM6 & 30 & 43 & 31 & 29 & 32 & 39 & 34 & 40 & 39 & 41 & 48 & 54 & 42 \\
\hline SEN & 18 & 20 & 15 & 13 & 14 & 14 & 15 & 16 & 15 & 16 & 15 & 15 & 15 \\
\hline Non-White & 92 & 60 & 46 & 45 & 37 & 32 & 38 & 30 & 29 & 29 & 22 & 11 & 27 \\
\hline Joined last 2 years & 2 & 4 & 31 & 26 & 7 & 3 & 5 & 5 & 6 & 4 & 3 & 1 & 7 \\
\hline
\end{tabular}

EAL pupils make more progress than average over their years of schooling, and they tend to make more progress the longer they have been labelled EAL (Table 36). By the end of KS4 those with the most years EAL have the highest attainment, confirming that EAL is not a good CA variable.

Table 36. Mean attainment scores of pupils by number of years EAL, England 2015

\begin{tabular}{lcccccccccccccc}
\hline & Never EAL & 1 & 2 & 3 & 4 & 5 & 6 & 7 & 8 & 9 & 10 & 11 & EverEAL \\
\hline KS1 points & 15 & 15 & 15 & 15 & 15 & 15 & 15 & 14 & 14 & 13 & 12 & 14 & 14 \\
KS2 points & 20 & 20 & 20 & 21 & 19 & 19 & 18 & 18 & 18 & 19 & 18 & 18 & 18 \\
KS1-KS2 VA & +0.1 & +0.2 & +0.2 & +0.0 & +0.5 & +0.4 & +0.4 & +0.3 & +0.4 & +0.8 & +1.1 & +0.2 & +0.1 \\
KS4 points & 307 & 295 & 261 & 283 & 290 & 319 & 310 & 313 & 319 & 320 & 326 & 324 & 311 \\
IDACI & 0.19 & 0.25 & 0.29 & 0.28 & 0.31 & 0.33 & 0.31 & 0.32 & 0.33 & 0.33 & 0.35 & 0.37 & 0.22 \\
\hline
\end{tabular}

This is also confirmed by consideration of attainment at the highest levels in KS5 (Table 37). However, EAL pupils are less likely to continue post-16, and so obtain the minimum level 3 qualification.

Table 37. Proportions of pupils continuing with post-16 education, by first language, England 2008

\begin{tabular}{lccccccc}
\hline & Not English & Column $\%$ & Row $\%$ & English & Column \% & Row \% & Total \\
\hline Total at KS4 & 59,453 & 100 & 10.0 & 535,347 & 100 & 90.0 & 594,800 \\
Continued post-16 & 37,300 & 62.7 & 11.9 & 276,337 & 51.6 & 88.1 & 313,637 \\
Achieved EE+ & 31,828 & 53.5 & 11.9 & 236,119 & 44.1 & 88.1 & 267,947 \\
Achieved CCC+ & 20,108 & 33.8 & 11.0 & 162,653 & 30.4 & 89.0 & 182,761 \\
Achieved ABB+ & 13,247 & 22.3 & 10.0 & 119,305 & 22.3 & 90.0 & 132,552 \\
\hline
\end{tabular}

Note. Not English includes EAL and not known.

\subsection{Special Educational Needs}

Pupils with any SEN are clearly more disadvantaged than those without, on most available indicators, and this is especially so for pupils with statements (Tables 38 and 39). They are much more likely to be FSM-eligible, speak a first language other than English, and to have arrived at their current school recently. 
Table 38. Percentage of pupils with specified characteristics by SEN category, England 2015

\begin{tabular}{lcccc}
\hline & No SEN & SEN no statement & SEN with statement & All pupils \\
\hline FSM-eligible & 11.6 & 24.8 & 31.3 & 14.1 \\
EverFSM6 & 28.6 & 49.4 & 52.9 & 32.3 \\
EAL & 15.1 & 13.3 & 9.9 & 14.7 \\
Non-White & 21.1 & 19.4 & 17.8 & 20.8 \\
Joined last 2 years & 2.9 & 3.9 & 5.1 & 3.1 \\
\hline
\end{tabular}

Table 39. Percentage of pupils with specified characteristics by SEN category, England 2015

\begin{tabular}{|c|c|c|c|c|c|c|c|}
\hline & No SEN & School Action & SEN support & School Action Plus & $\begin{array}{l}\text { Education health } \\
\text { and care plan }\end{array}$ & $\begin{array}{l}\text { SEN other } \\
\text { statement }\end{array}$ & All pupils \\
\hline FSM-eligible & 11.6 & 21.3 & 24.7 & 31.8 & 31.8 & 31.2 & 14.1 \\
\hline EverFSM6 & 28.6 & 44.5 & 49.3 & 58.5 & 54.3 & 52.7 & 32.3 \\
\hline EAL & 15.1 & 16.2 & 12.5 & 13.0 & 10.0 & 9.8 & 14.7 \\
\hline Non-White & 20.8 & 20.8 & $*$ & 18.9 & $*$ & 17.9 & 20.8 \\
\hline Joined last 2 years & 2.9 & 3.0 & 4.1 & 4.8 & 6.2 & 5.0 & 3.1 \\
\hline
\end{tabular}

There is a corresponding picture in terms of attainment at each Key Stage (Tables 40 and 41). Not surprisingly, pupils with the most serious SENs have the lowest average attainment and make the least progress between phases of education.

Table 40. Mean attainment scores of pupils by SEN category, England 2015

\begin{tabular}{lcccc}
\hline & No SEN & SEN no statement & SEN with statement & All pupils \\
\hline KS1 average points & 16.10 & 12.33 & 7.66 & 15.23 \\
KS2 average points & 20.77 & 17.34 & 11.17 & 20.10 \\
KS1 to KS2 VA & +0.22 & -0.43 & -0.65 & +0.10 \\
KS4 capped points & 330.42 & 224.68 & 114.32 & 308.12 \\
IDACI score & 0.21 & 0.26 & 0.25 & 0.22 \\
\hline
\end{tabular}

Table 41. Mean attainment scores of pupils by SEN category, England 2015

\begin{tabular}{lccccccc}
\hline & No SEN & School Action & SEN support & $\begin{array}{c}\text { School } \\
\text { Action Plus }\end{array}$ & $\begin{array}{c}\text { Education health } \\
\text { and care plan }\end{array}$ & $\begin{array}{c}\text { SEN other } \\
\text { statement }\end{array}$ & All pupils \\
\hline KS1 average points & 16.10 & 12.47 & 12.31 & 12.22 & 8.43 & 7.57 & 15.23 \\
KS2 average points & 20.77 & 17.52 & 17.31 & 17.17 & 15.27 & 15.39 & 20.10 \\
KS1 to KS2 VA & +0.22 & -0.41 & -0.47 & -0.24 & -0.60 & -0.65 & +0.10 \\
KS4 capped points & 330.42 & 247.89 & 224.53 & 184.37 & 138.99 & 111.27 & 308.12 \\
IDACI score & 0.21 & 0.26 & 0.26 & 0.29 & 0.26 & 0.25 & 0.22 \\
\hline
\end{tabular}

In 2015, no pupils have a missing value recorded for SEN, although there are an increasing number of missing values when going back through each prior year at school for these pupils. A large number (215,442 or 38.4\%) of pupils have altered their SEN status from 2006 to 2015. Overall, the pupils with changed SEN status have similar characteristics to those with unchanged SEN status (Table 42). Some are temporarily recorded as SEN, some move from SEN in primary school to not SEN in secondary, some are diagnosed later, and some move between different forms of SEN over time. 
Table 42. Percentage of pupils with specified characteristics with and without changed SEN category, SEN pupils, England 2015

\begin{tabular}{lcc}
\hline & Changed SEN & Permanent SEN \\
\hline FSM-eligible & 26.1 & 27.8 \\
EverFSM6 & 50.8 & 45.5 \\
English as additional language & 87.8 & 85.4 \\
Non-White ethnic origin & 21.5 & 20.3 \\
Joined school in last two years & 4.2 & 4.0 \\
\hline
\end{tabular}

Despite having similar characteristics to the others (above), the pupils with permanent SEN status have much lower average attainment in every respect than SEN pupils with changes in their status (Table 43). The gap is largest at KS4, and it may be that the treatment or extra assistance given to some SEN pupils means that they are closer to non-SEN pupils by the time they reach the age of 16 , and have changed their reported status. However, other pupils continue to need assistance and would continue to need it if they participated in post- 16 and higher education. Therefore SEN status in the most recent year would be the most appropriate variable if SEN were to be used for CA.

Table 43. Mean attainment scores of pupils with and without changed SEN category, SEN pupils, England 2015

\begin{tabular}{lcc}
\hline & Changed SEN & Permanent SEN \\
\hline Key Stage 1 average points & 11.77 & 7.15 \\
Key Stage 2 average points & 17.06 & 15.62 \\
Key Stage 1 to KS2 VA score & -0.50 & -0.36 \\
Key Stage 4 capped points & 210.14 & 121.88 \\
IDACI score & 0.26 & 0.24 \\
\hline
\end{tabular}

To cope to some extent with volatility in the FSM-eligibility indicator, the DfE use a measure EverFSM to signify a pupil who has been FSM-eligible at any time over a number of years. We propose a similar indicator-EverSEN_-signifying whether a pupil has ever been known to have been recorded as SEN in the 10 years from early primary to the end of KS4. However, we have criticised the EverFSM measure as being insensitive to levels and permanence of poverty, and so use the number of years known to be FSM-eligible as a better indicator. We propose the same here - and so also use the number of years a pupil is known to have been SEN.

There is a clear, consistent gradient of poverty associated with every year of being recorded as SEN (Table 44). The number of years a pupil is listed as SEN is therefore a promising indicator, but is perhaps a proxy for other forms of disadvantage. The exceptions are that pupils with chronic SEN are actually less likely to speak English as an additional language, and more likely to be White than non-SEN pupils. It is possible that EAL is being partly misdiagnosed or treated as SEN in the pupil's early school years in England, but that once English fluency is attained this no longer occurs.

Table 44. Percentage of pupils with specified characteristics by number of years SEN, England 2015

\begin{tabular}{|c|c|c|c|c|c|c|c|c|c|c|c|c|}
\hline & Never SEN & 1 year & 2 years & 3 years & 4 years & 5 years & 6 years & 7 years & 8 years & 9 years & 10 years & EverSEN \\
\hline FSM-eligible & 8.7 & 16.0 & 17.7 & 19.5 & 19.9 & 21.4 & 22.2 & 23.9 & 25.5 & 27.3 & 28.7 & 22.9 \\
\hline EverFSM6 & 22.9 & 37.2 & 40.5 & 42.6 & 44.1 & 46.1 & 47.6 & 50.1 & 52.4 & 54.5 & 52.0 & 46.1 \\
\hline EAL & 14.4 & 18.5 & 19.0 & 18.5 & 17.7 & 16.8 & 14.1 & 13.2 & 12.1 & 10.7 & 9.2 & 15.0 \\
\hline Non-White & 20.2 & 23.8 & 24.3 & 24.6 & 23.8 & 23.9 & 20.8 & 20.4 & 19.2 & 18.3 & 16.8 & 20.8 \\
\hline Joined last 2 years & 2.8 & 4.2 & 3.8 & 3.5 & 3.4 & 3.4 & 3.6 & 4.1 & 4.3 & 4.0 & 2.8 & 3.6 \\
\hline
\end{tabular}


The same clear gradient occurs with attainment - the longer a pupil has been recorded as SEN the lower their attainment and progress is at any age (Table 45). The most promising versions of this indicator would be the most recent (as above), for those with statements of SEN, and coupled with the number of years reported as SEN during schooling.

Table 45. Mean attainment scores of pupils by number of years SEN, England 2015

\begin{tabular}{lcccccccccccc}
\hline & $\begin{array}{c}\text { Never } \\
\text { SEN }\end{array}$ & 1 & 2 & 3 & 4 & 5 & 6 & 7 & 8 & 9 & $\begin{array}{c}\text { EverS } \\
\text { EN }\end{array}$ \\
\hline KS1 pts & 17.2 & 15.4 & 14.7 & 14.2 & 13.7 & 13.0 & 12.6 & 12.1 & 11.5 & 10.6 & 8.6 & 12.4 \\
KS2 pts & 21.8 & 19.8 & 19.2 & 18.9 & 18.3 & 18.0 & 17.6 & 17.2 & 16.7 & 16.1 & 15.6 & 17.8 \\
KS1-2 VA & +0.2 & -0.0 & +0.0 & +0.1 & +0.1 & +0.4 & +0.3 & +0.0 & -0.1 & -0.3 & -0.6 & -0.1 \\
KS4 pts & 350 & 302 & 292 & 281.5 & 275 & 263 & 247 & 235 & 220 & 203 & 161 & 247 \\
IDACI & 0.20 & 0.24 & 0.25 & 0.25 & 0.26 & 0.26 & 0.26 & 0.26 & 0.26 & 0.27 & 0.26 & 0.26 \\
\hline
\end{tabular}

It is clear that SEN pupils are much less likely than average to continue in education post-16, and even less likely to obtain the sort of qualifications permitting entry to HE under the current system (Tables 46 and 47). 26\% of non-SEN students achieved ABB+ at KS5 in 2008, compared to less than 3\% of those with statements of SEN. Whatever provision for help those statements put in place it is clearly not enough to allow easy access to HE. All of this makes SEN a promising indicator for CA.

Table 46. Proportions of pupils continuing with post-16 education, by SEN, England 2008

\begin{tabular}{lccccccc}
\hline & Non-SEN & Column $\%$ & Row $\%$ & SEN & Column $\%$ & Row \% & Total \\
\hline Total at KS4 & 485,980 & 100 & 81.7 & 108,820 & 100 & 18.3 & 594,800 \\
Continued post-16 & 292,891 & 60.3 & 93.4 & 20,746 & 19.1 & 6.6 & 313,637 \\
Achieved EE+ & 251,693 & 51.8 & 93.9 & 16,254 & 14.9 & 6.1 & 267,947 \\
Achieved CCC+ & 174,649 & 35.9 & 95.6 & 8,112 & 7.5 & 4.4 & 182,761 \\
Achieved ABB+ & 127,528 & 26.2 & 96.2 & 5,024 & 4.6 & 3.8 & 132552 \\
\hline
\end{tabular}

Table 47. Proportions of pupils continuing with post-16 education, by SEN, England 2008

\begin{tabular}{lccccc}
\hline & School Action & None & School Action Plus & Statement & Total \\
\hline Total students at KS4 & 58,130 & 485,980 & 26,617 & 24,073 & 594,800 \\
Continued post-16 & 23.7 & 60.3 & 16.4 & 10.9 & 52.7 \\
Achieved EE+ & 18.7 & 51.8 & 12.5 & 8.4 & 45.0 \\
Achieved CCC+ & 9.2 & 35.9 & 6.2 & 4.5 & 30.7 \\
Achieved ABB+ & 5.6 & 26.2 & 3.9 & 2.8 & 22.3 \\
\hline
\end{tabular}

\subsection{Age in Year}

In England, almost all children attend school with an age cohort of whom the oldest was born on 1st September of one year, and the youngest was born almost a year later on 31st August of the following year. The precise age of a child or young person within their school year cohort has been shown to be strongly linked to their success in attainment, later life, and their wider personal development. This becomes a continuing problem, because although the relevance of an age gap of one year might seem less at age 18 or 21, the young person has by then had 12 or more years of schooling as the youngest, least mature, and maybe the smallest person in their year. The summer-born pupils are less likely to be picked for competitive sports and more likely to be bullied. Could age in year be used as a factor in contextualised admissions? 
As would be expected, pupils who are younger in the year are no more likely to be from poor families or particular ethnic minorities, or to be more mobile between schools in both the 2012 and the 2015 cohort (Tables 48 and 49). However, they are more likely to be labelled as having a Special Educational Need (SEN) and perhaps slightly more likely to be recorded as EAL. This is presumably because of their lower average attainment throughout their school career, culminating in them being less likely to reach the official level 2 benchmark English and maths at KS4. Again this casts some doubt on the validity of SEN as an indicator.

Table 48. Percentage of pupils with specified characteristics by age in months (January 2012), England 2012

\begin{tabular}{|c|c|c|c|c|c|c|c|c|c|c|c|c|}
\hline Age in months & 184 & 185 & 186 & 187 & 188 & 189 & 190 & 191 & 192 & 193 & 194 & 195 \\
\hline FSM-eligible & 14.6 & 14.2 & 14.4 & 14.2 & 14.0 & 14.1 & 14.4 & 15.0 & 14.8 & 14.1 & 13.9 & 13.6 \\
\hline SEN & 31.3 & 31.2 & 31.2 & 31.0 & 29.9 & 30.3 & 29.9 & 30.0 & 29.2 & 29.2 & 28.1 & 28.0 \\
\hline Non-White & 25.8 & 25.8 & 26.2 & 26.6 & 26.3 & 26.6 & 26.9 & 28.0 & 28.0 & 26.9 & 27.1 & 26.8 \\
\hline EAL & 20.2 & 20.2 & 20.7 & 21.1 & 20.8 & 21.1 & 22.3 & 23.6 & 22.0 & 21.2 & 21.2 & 21.2 \\
\hline Joined last 2 years & 3.1 & 3.1 & 3.1 & 3.1 & 3.1 & 3.1 & 3.2 & 3.3 & 3.3 & 3.3 & 3.1 & 3.3 \\
\hline KS4 Level 2 EM & 55.4 & 56.2 & 57.3 & 57.8 & 59.0 & 58.7 & 59.0 & 59.0 & 60.1 & 61.1 & 62.5 & 62.5 \\
\hline
\end{tabular}

Note. There were around 50,000 pupils born in each month. Pupils born outside these 12 months are ignored.

Table 49. Percentage of pupils with specified characteristics by age in months (January 2015), England 2015

\begin{tabular}{lcccccccccccc}
\hline Age in months & 184 & 185 & 186 & 187 & 188 & 189 & 190 & 191 & 192 & 193 & 194 & 195 \\
\hline FSM-eligible & 14.4 & 14.0 & 14.2 & 13.8 & 13.7 & 14.0 & 14.2 & 14.9 & 14.5 & 14.1 & 13.9 & 13.7 \\
EverFSM6 & 33.1 & 32.2 & 31.8 & 31.5 & 31.4 & 32.3 & 32.7 & 33.8 & 33.2 & 32.5 & 32.1 & 31.5 \\
SEN & 19.2 & 18.2 & 17.9 & 17.5 & 17.4 & 17.2 & 16.8 & 16.4 & 16.5 & 15.7 & 15.5 & 15.0 \\
Non-White & 20.8 & 20.6 & 20.2 & 20.4 & 20.2 & 20.1 & 20.0 & 22.2 & 21.6 & 21.0 & 20.6 & 19.7 \\
EAL & 15.6 & 15.6 & 24.3 & 14.3 & 14.2 & 14.3 & 14.1 & 16.0 & 14.9 & 14.5 & 14.3 & 13.3 \\
Joined last 2 years & 2.8 & 3.1 & 3.0 & 2.8 & 3.0 & 2.9 & 3.0 & 3.2 & 3.1 & 3.1 & 3.0 & 2.9 \\
\hline
\end{tabular}

Note. There were around 48,000 pupils born in each month. Pupils born outside these 12 months are ignored.

At every phase of schooling, older pupils have higher average attainment than younger pupils in almost direct proportion to their difference in age within their year group (Tables 50 and 51). The gap between the oldest and youngest at $\mathrm{KS} 1$ in 2012 is $\mathrm{ES}=0.58$, at $\mathrm{KS} 2$ it is 0.34 , and at KS4 it is 0.11 (for both total and capped points scores). There is even a gap of 0.13 in entries at KS4. This is an inherent but probably unavoidable unfairness caused by an arbitrary date of entry to school.

Table 50. Mean attainment scores of pupils by age in months (January 2012), England 2012

\begin{tabular}{|c|c|c|c|c|c|c|c|c|c|c|c|c|}
\hline & 184 & 185 & 186 & 187 & 188 & 189 & 190 & 191 & 192 & 193 & 194 & 195 \\
\hline KS1 points & 14.3 & 14.5 & 14.8 & 15.0 & 15.2 & 15.4 & 15.6 & 15.8 & 16.0 & 16.3 & 16.5 & 16.6 \\
\hline $\mathrm{KS} 2$ points & 27.0 & 27.1 & 27.3 & 27.4 & 27.6 & 27.7 & 27.7 & 27.8 & 28.0 & 28.2 & 28.4 & 28.4 \\
\hline KS2 VA & -0.04 & -0.03 & -0.02 & -0.09 & -0.05 & -0.07 & -0.09 & -0.08 & -0.07 & -0.05 & -0.02 & -0.03 \\
\hline KS4 Entries & 7.4 & 7.5 & 7.5 & 7.6 & 7.6 & 7.6 & 7.6 & 7.6 & 7.7 & 7.7 & 7.8 & 7.8 \\
\hline KS4 total & 460 & 463 & 465 & 466 & 470 & 468 & 469 & 468 & 473 & 474 & 480 & 478 \\
\hline KS4 capped & 334 & 335 & 337 & 337 & 339 & 339 & 339 & 338 & 341 & 341 & 344 & 343 \\
\hline KS4 B8 CVA & +1.2 & +1.1 & +0.6 & +0.1 & -0.4 & -1.9 & -2.8 & -3.8 & -4.5 & -6.3 & -5.5 & -6.2 \\
\hline
\end{tabular}

Note. Overall SD 3.99, 4.24, 2.36. 3.00. 177.87, 96.97, 66.85 . 
Table 51. Mean attainment scores of pupils by age in months (January 2015), England 2015

\begin{tabular}{lcccccccccccc}
\hline & 184 & 185 & 186 & 187 & 188 & 189 & 190 & 191 & 192 & 193 & 194 & 195 \\
\hline KS1 points & 14.1 & 14.3 & 14.5 & 14.7 & 14.9 & 15.1 & 15.3 & 15.5 & 15.7 & 16.0 & 16.2 & 16.4 \\
KS2 points & 19.5 & 19.7 & 19.8 & 19.9 & 19.9 & 20.1 & 20.3 & 20.1 & 20.2 & 20.4 & 20.6 & 20.7 \\
KS2 VA & +0.1 & +0.1 & +0.1 & +0.1 & +0.1 & +0.1 & +0.1 & +0.1 & +0.1 & +0.1 & +0.1 & +0.2 \\
KS4 capped & 301 & 304 & 305 & 307 & 308 & 308 & 308 & 309 & 310 & 312 & 315 & 316 \\
IDACI & 0.22 & 0.22 & 0.22 & 0.22 & 0.22 & 0.22 & 0.22 & 0.23 & 0.22 & 0.22 & 0.22 & 0.22 \\
\hline
\end{tabular}

Given that the level of recorded disadvantage is the same for each month of birth, only age can explain the systematic difference in attainment. The simplest way to deal with this would be to routinely age-standardise all attainment scores (Gorard, 2015). Age would then be an easy to handle CA variable that would reduce unfairness for summer-born children (but perhaps not eliminate it entirely because of the enduring impact of early experiences). Age is a clear, valid, and reliable indicator, collected officially, available from all applicants, and it can be easily verified. Age is probably the single best CA variable available for use. Age in year is currently ignored because it is not seen as an issue for widening participation for some reason (although it was used for the same reasons of justice in school CVA until 2010).

\subsection{Sex}

Male and female students are, as would be expected, very similar in all known respects-levels of poverty, ethnic origin, first language, age in year, and school mobility (Tables 52 and 53). However, males are much more likely to be labelled as having SEN, and have markedly lower attainment results at all phases of schooling. These differences cannot be explained by their differential background, and if sex were almost any other characteristic it would already have been proposed and used widely for contextualised admissions. The variable is a relatively clear one (perhaps the second clearest available after age), routinely collected and available to HEIs at time of admission. As with age, there is an argument that all attainment results should be sex-standardised, using student sex for CA. This would help to balance the intakes to HEIs better.

Table 52. Percentage of pupils with specified characteristics by reported sex, England 2015

\begin{tabular}{lcc}
\hline & Female & Male \\
\hline FSM 2005 & 16.9 & 16.5 \\
FSM 2015 & 14.0 & 14.2 \\
EverFSM6 & 32.4 & 32.2 \\
Non-White & 20.7 & 20.8 \\
English as additional language & 14.6 & 14.7 \\
Ever EAL & 19.4 & 19.5 \\
SEN & 12.9 & 21.0 \\
Ever SEN & 33.0 & 47.6 \\
Joined school in last two years & 3.3 & 3.0 \\
KS4 Level EM & 60.5 & 50.6 \\
\hline
\end{tabular}

Table 53. Mean attainment scores of pupils by reported sex, England 2015

\begin{tabular}{lcc}
\hline & Female & Male \\
\hline Key Stage 1 average points & 15.77 & 14.72 \\
Key Stage 2 average points & 26.37 & 25.66 \\
Key Stage 1 to 2 VA score & +0.10 & +0.09 \\
Key Stage 4 capped points & 322.8 & 294.2 \\
\hline
\end{tabular}




\begin{tabular}{lcc}
\hline IDACI score 2015 & 0.22 & 0.22 \\
Age in months & 69.5 & 69.5 \\
Years EAL & 1.4 & 1.4 \\
Years SEN & 1.58 & 2.71 \\
\hline
\end{tabular}

Substantially fewer male than female student continue in education post-16, and fewer again attain any Level 3 qualifications (Table 54). The attainment gap at $\mathrm{ABB}+$ is 16.5 , while it is 10.2 at $\mathrm{EE}+$, and the post-16 participation gap is only 8.5 . This is one the few gaps that worsens in post-16 education. This strongly suggests the need for sex of student as a CA variable.

Table 54. Proportions of pupils continuing with post-16 education, by sex, all pupils in England 2008

\begin{tabular}{lccccccc}
\hline & Male & Column $\%$ & Row $\%$ & Female & Column \% & Row \% & Total \\
\hline Total at KS4 & 302,735 & 100 & 50.9 & 292,065 & 100 & 49.1 & 594,800 \\
Continued post-16 & 146,210 & 48.3 & 46.6 & 167,427 & 57.3 & 53.4 & 313,637 \\
Achieved EE+ & 122,752 & 40.5 & 45.8 & 145,195 & 49.7 & 54.2 & 267,947 \\
Achieved CCC+ & 79,599 & 26.3 & 43.6 & 103,162 & 35.3 & 56.4 & 182,761 \\
Achieved ABB+ & 56,469 & 18.7 & 42.6 & 76,083 & 26.1 & 57.4 & 132,552 \\
\hline
\end{tabular}

\section{Discussion}

Similar analyses to those above have been conducted with the datasets from 2008, 2012, 2014 and 2015, but not all are presented here. In all important respects the results are the same. The main difference is that the level of missing data tends to decline with each cohort. Missing data cannot be used in itself as an indicator of disadvantage, even though students missing key data appear to be the most disadvantaged and lowest attaining on average.

Of the indicators considered here, five would be inappropriate for use in contextualised admissions. These are IDACI scores, school type, relative school context, ethnicity and first language.

Like most indicators, IDACI has problems with missing data, but unlike them is proposed for use partly because other indicators have missing data. It is unstable over time, and is not a fair focus on disadvantage - partly because most disadvantaged students do not live in the most disadvantaged areas.

The problem with school types is that there are so many, and most types have greater disadvantage and lower attainment than mainstream state-maintained schools. For example, it is hard to envisage an argument for offering assistance to applicants from state-maintained non-selective schools over those from mainstream independent schools that would not also suggest offering assistance to students from special schools and hospitals over mainstream state-maintained schools. Should students in independent special schools be treated as being from special or independent schools? What about the fact that students from special schools will rarely come close to a level of attainment that is currently needed to enter HE? Which school would be used in CA - the first, last or modal? It is almost certainly better to focus on individual characteristics.

The relative disadvantage of others in a school makes no clear difference to individual pupil outcomes, nor does the average attainment of others in the same school. Neither is appropriate to use for CA.

It is clear that some ethnic minority students are also disadvantaged (and Black students are under-represented at the higher levels of attainment at KS5), but it is not so clear that minority ethnicity is any kind of disadvantage in itself, and that it would not be picked up by other indicators.

Students who speak a first language other than English when they start school catch-up and eventually overtake their peers by KS4, on average. They are less likely to continue to KS5, but as likely to attain ABB or better at A-level. This does not make first language a good general variable for CA.

Living in care is only relevant to a few cases, and is clearly linked to higher disadvantage and lower attainment on average. It would be appropriate to apply this as a CA variable in all reported cases. 
Of the other indicators considered here, SEN and FSM would be appropriate for use in contextualised admissions, although neither is without problems.

SEN students tend not to catch up with their peers in the way that EAL students do, making it a stronger indicator of disadvantage in HE. The validity of SEN is slightly compromised by the appearance that EAL is substituted for it for at least some ethnic minorities, by its inexplicable link to age in year, and by the fact that it covers a wide range of issues. There is also a danger for justice that the label SEN will be used to provide CA for those with less severe challenges, so improving a headline figure, while leaving the position of the most disadvantaged unchanged. At heart, the issue is the same as for special schools and hospitals-the most disadvantaged students would often not attain the level of prior qualification that would permit the current style of CA to operate. The most suitable year for SEN would be the most recent available, coupled with the number of years a student has been known to have a statement of SEN.

Eligibility for FSM is perhaps the most easily and widely applicable variable for CA. The number of cases missing values is being reduced over time, and the number of years eligible is a good proxy for level of deprivation and associated lower than expected progress at school. However, there are signs that FSM-eligible students are already proportionately represented in HE, and that any problems lie in the decision to continue after KS4 or not.

Of the other indicators considered here, two would be very appropriate for use in contextualised admissions, and are almost without problems. Age in year and sex are clearly linked to lower attainment at school, and lower participation in HE, than can be justified by the evidence. The age and sex of students are simple readily available variables, and their related attainment gaps are easy to fix. Doing so would greatly increase fairness in admissions to HE. The problem is that neither is currently seen as a priority by policy-makers. The unfairness of summer born in HE is somehow less visible than for school type or ethnicity, for example, even though as this paper shows the unfairness in terms of school type and ethnicity is nowhere near as clear analytically.

\section{Acknowledgements}

This work was funded by the ESRC: grant numbers ES/N012046/1 and ES/N01166X/1.

\section{References}

BIS. (2013). Widening participation in higher education. London: Department for Business Innovation and Skills. Retrieved from https://www.gov.uk/government/uploads/system/uploads/attachment_data/file/226357/13-P155-widening-p art-HE-2013.pdf

Broecke, S. (2015). University rankings: Do they matter in the UK? Education Economics, 23(2), 137-161. https://doi.org/10.1080/09645292.2012.729328

Gorard, S. (2000). Education and Social Justice. Cardiff: University of Wales Press.

Gorard, S. (2006). Is there a school mix effect? Educational Review, 58(1), 87-94. https://doi.org/10.1080/00131910500352739

Gorard, S. (2010). Serious doubts about school effectiveness. British Educational Research Journal, 36(5), 735-766. https://doi.org/10.1080/01411920903144251

Gorard, S. (2015). The easy way to help kids born in summer keep up at school. In New Scientist (p. 29).

Gorard, S., Adnett, N., May, H., Slack, K., Smith, E., \& Thomas, L. (2007). Overcoming barriers to HE. Stoke-on-Trent: Trentham Books.

Jerrim, J., \& Vignoles, A. (2015). University access for disadvantaged children: A comparison across countries. Higher Education, 70(6), 903-921. https://doi.org/10.1007/s10734-015-9878-6

Universities Scotland. (2016). Futures not backgrounds. Edinburgh: Universities Scotland. Retrieved from http://www.universities-scotland.ac.uk/wp-content/uploads/2016/09/10537-\%E2\%80\%A2-Futures-Not-Bac kgrounds-web.pdf

\section{Copyrights}

Copyright for this article is retained by the author(s), with first publication rights granted to the journal.

This is an open-access article distributed under the terms and conditions of the Creative Commons Attribution license (http://creativecommons.org/licenses/by/4.0/). 